\title{
Prevalence, risk factors and metabolic predictors associated with subclinical ketosis on dairy cattle in Batna, Eastern of Algeria
}

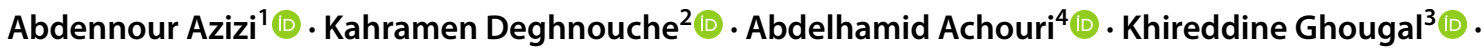 \\ Madjid Tlidjane $^{1}$ - Eliel González-García ${ }^{5}$
}

Received: 19 April 2021 / Accepted: 31 December 2021

(c) The Author(s), under exclusive licence to Springer-Verlag London Ltd., part of Springer Nature 2022

\begin{abstract}
Economic impact of subclinical ketosis (SCK) in dairy herds resulted from a decreased productivity, reproductive performances, and health condition. In Algeria, data availability regarding the prevalence of SCK in dairy cows were limited. The present study is a contribution in that direction and aimed to determine the prevalence of SCK between 2 and 50 days postpartum whereas investigating herd- and cow-level risk factors and the metabolic profile associated, on two bovine populations imported and native. The study was conducted with 16 typical representative local dairy cow herds $(n=100 ; 2-12$ years old; located at Merouana, Batna Province) with data collected in a period comprised between August and February of the following year. Concentration of cows' plasma beta-hydroxybutyrate (BHBA) was used for the diagnosis, with values equal or higher than $1.2 \mathrm{mmol} / \mathrm{L}$ chosen as the threshold for SCK detection. Other key associated zootechnical parameters such as body condition score (BCS) were monitored at the same sampling points. Logistic regression analyses were carried out to characterize association between parameters. The average SCK prevalence was $9 \%$ and resulted highest during first- and second-week postcalving, with a peak in the first week. The herd size $(<30$ lactating cows $)$ and BCS $(\leq 3)$ were risk factors associated with SCK prevalence. At the cow-level, risks of SCK increased in thin individuals $(P=0.058$; odds ratio $(\mathrm{OR})=5.00,95 \%$ confidence interval $(\mathrm{CI})=0.95-26.32)$. At the herd-level, risks of SCK increased in smaller frame size herds $(P=0.047 ; \mathrm{OR}=8.76,95 \% \mathrm{CI}=1.03-74.49)$. Most cases of SCK were observed in native cows compared to imported. Interestingly, linear stepwise regression showed a good relationship between BHBA and total bilirubin $\left(P=0.0001 ; R^{2}=0.59\right)$. There were significant differences between healthy and ketotic cows regarding plasma concentration of bilirubin $(P=0.003)$, glucose $(P=0.001)$, alanine aminotransferase (ALT) $(P=0.008)$, creatinine $(P=0.007)$, and sodium $(P=0.02)$. According to receiver operating characteristic (ROC) curve analysis, the best parameter for SCK prediction is total bilirubin with more than $4.09 \mathrm{~g} / \mathrm{L}$ as a cutoff point ( $77.78 \%$ sensitivity and $94.51 \%$ specificity). According to metabolic profile and feeding data we suggest that most cases of SCK observed in our study are type I. Further studies are required to validate other metabolic predictors for SCK and investigate adaptation of imported cows in semiarid regions in Algeria.
\end{abstract}

Keywords Subclinical ketosis $\cdot$ Dairy cattle $\cdot$ Prevalence $\cdot$ Risk factors $\cdot$ Metabolic profile

Abdennour Azizi

abdennour.azizi@univ-batna.dz

1 Department of Veterinary Science, Veterinary Sciences and Agricultural Sciences Institute, University of Batna 1, 05000 Batna, Algeria

2 Department of Agricultural Sciences, Faculty of Exact, Natural and Life Sciences, University of Biskra, 07000 Biskra, Algeria
3 Department of Veterinary Science, Veterinary Science Institute, University of Constantine 1, 25000 Constantine, Algeria

4 Department of Veterinary Science, Agricultural and Veterinary Sciences Institute, University of Souk Ahras, 41000 Souk Ahras, Algeria

5 SELMET, INRAE, CIRAD, Montpellier SupAgro, University Montpellier, 34060 Montpellier, France 


\section{Introduction}

The cow peripartum or transition period goes from the 3 weeks before and 3 weeks after the calving date. This key period is a strong determinant of the full lactation success regarding cows' health and performance (Duffield et al. 2009). In early lactation, negative energy balance (NEB) is a common phenomenon in high yielding cattle, in which energy requirement for milk production increase and exceed energy intake. The normal adaptive response of cows through the peripartum involves complex and synchronized physiological adjustments in energy intake and basal energy requirements for maintenance. In contrast, a poor or a limited adaptive capacity response might alter homeostasis and induce NEB, which responsible of increased risks of possible periparturient diseases (Herdt 2000). A prolonged NEB deemed to be associated with ketosis development (Ingvartsen 2006).

Blood BHBA (beta-hydroxybutyrate) determination was considered as the gold standard test for ketosis diagnosis because of its predominance and stability in blood compared to other ketone bodies (acetone or acetoacetate) (Oetzel 2004). The common BHBA analysis in laboratory used for ketosis diagnosis are, however, time consuming and expensive for large sample sizes, as it's the case of carrying out diagnosis in herds belonging to real-producing farms. Recently, electronic hand-held devices, initially developed for human BHBA determination has been used as cowside ketosis diagnosis, and showed excellent test results (Iwersen et al. 2009; Voyvoda a Erdogan 2010).

Two different forms of hyperketonemia differing in their clinical, frequency and importance has been commonly reported, where clinical and subclinical ketosis (SCK) both result in increased concentrations of ketone bodies in the tissues and milk of the cows (Enjalbert et al. 2001). The clinical form of ketosis is generally easy to diagnose and has lesser incidence, whereas the subclinical form is more prevalent and even more difficult to detect.

The most commonly used cut-off for SCK definition in dairy cattle is blood, plasma, or serum BHBA concentration at the threshold value equal or exceed $1.2 \mathrm{mmol} / \mathrm{L}$ (Ospina et al. 2010; McArt et al. 2012; Suthar et al. 2013; Garro et al. 2014; Tatone et al. 2016). Previous research reported an overall prevalence of cow's SCK ranges from 8.9 to $34 \%$ in the first two months of lactation (Duffield 2000). Recently, the peak prevalence of SCK was observed in the first two weeks of lactation, ranging from 20 to $43 \%$ (Duffield et al. 2009; Chapinal et al. 2011; McArt et al. 2012; Suthar et al. 2013; Berge and Vertenten 2014; Tatone et al. 2016).

The SCK provokes significant direct and indirect economic losses in dairy herds, respectively by decreasing milk production and increasing the occurrence of peripartum diseases (Oetzel 2004). Furthermore, increased concentration of BHBA can affect milk production and reproduction, and increase the risk of subsequent peripartum diseases (Duffield et al. 2009; McArt et al. 2013; Suthar et al. 2013).

Currently, limited data on the prevalence of SCK in dairy cows' herds in Algeria are available. The present study is a contribution in that direction and aimed to determine the prevalence of SCK in postpartum whereas investigating herd- and cow-level risk factors and the metabolic profile associated, on two bovine populations imported and native.

\section{Materials and methods}

\section{Study area}

The study was carried out in Merouana, District of Batna Province, located in the eastern of Algeria, between $35^{\circ}$ $38^{\prime} \mathrm{N}$ latitude and $5^{\circ} 55^{\prime} \mathrm{E}$ longitude, with area of 509.97 $\mathrm{km}^{2}$ (Fig. 1). Merouana has a semiarid climate with an annual average of pluviometry varies between 416.7 and $376.8 \mathrm{~mm}$. The veterinary services of the district record 120 herds owners, having approximately 2810 dairy cows, composed genetically of native or crossbred and exotic or purebred (Direction des Services Agricoles de la Wilaya de Batna 2020).

\section{Sample size determination}

The total sample size for the present study is determined using the formula of prevalence studies as follows: $n=\frac{Z^{2} P(1-P)}{d^{2}}$ (Pourhoseingholi et al. 2013);

where $n$ is the sample size, $Z$ is the statistic corresponding to level of confidence, $P$ is the expected prevalence obtained from previous study or a pilot study, and $d$ is the precision corresponding to effect size. The confidence level and the precision used in our study were, respectively, $95 \%$ and $10 \%$. The prevalence of SCK $(50 \%)$ in the eastern of Algeria reported by Tlidjane et al. (2004) was used as the expected prevalence value. By applying these values in the formula, the sample size calculated was 96 , which was rounded to 100 cows to be selected in our study.

\section{Study population}

The sampled cows were checked clinically for the presence of metabolic and infectious peripartum diseases (clinical ketosis, displaced abomasum, mastitis, retained placenta, metritis, milk fever, and lameness). The study was conducted from August to February of the following year. The experimental cows ( $n=100$ clinically healthy; $2-12$ years old) were randomly selected from 16 dairy herds around the District of Merouana (Batna Province, Algeria) and were finally 


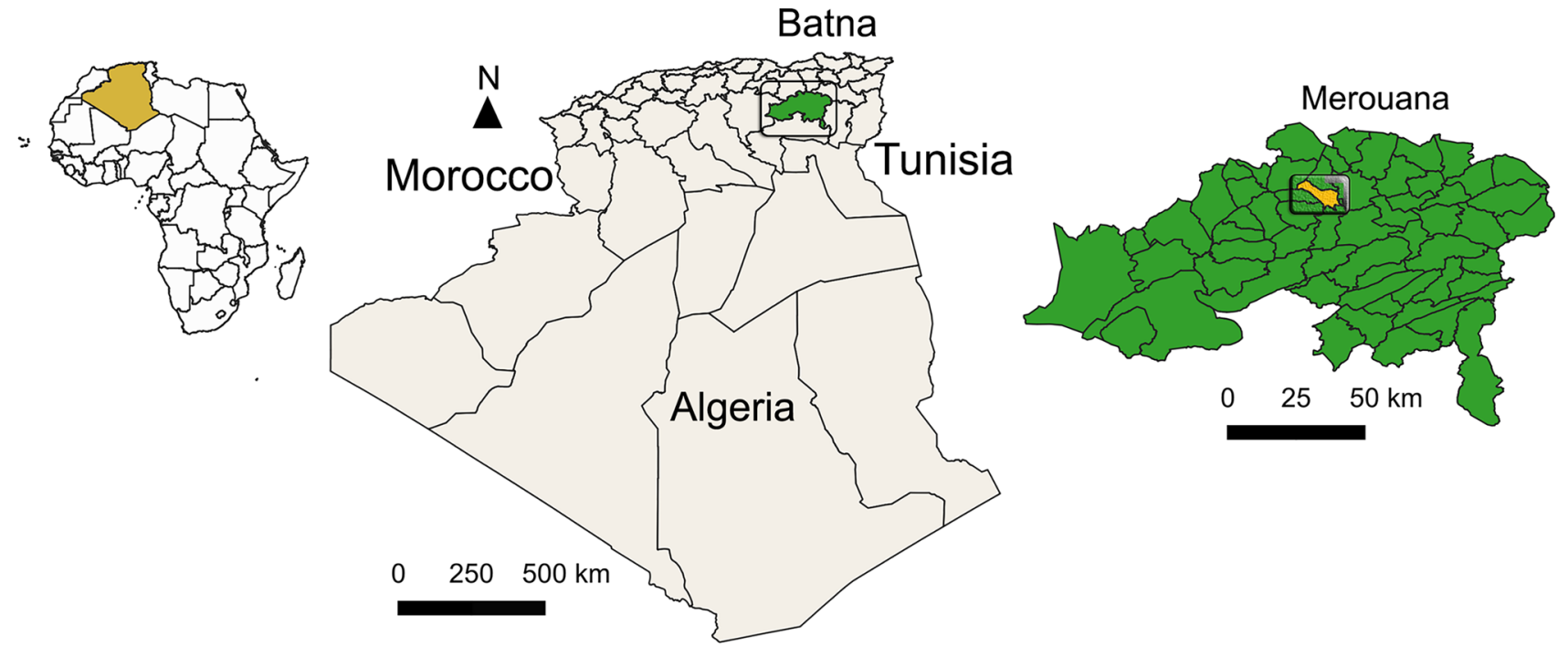

Fig. 1 Geographical location of Merouana District, Batna Province, Algeria

composed by native or crossbred cows $(n=56)$ and imported or exotic European purebred cows ( $n=44 ; 23$ Holstein and 21 Fleckvieh). The study cows were composed of 37 primiparous and 63 multiparous. The lactation number ranged from one to 10. All herds were overall composed by less than 50 cows without calving concentration strategy (the calving occurring throughout the year). During lactation, cows were milked mechanically and have their concentrate portions, twice a day.

\section{Data collection}

The body condition score (BCS) was determined at the sampling day by a single observer, using a 1 to 5 scale with 0.25 increments as described by Edmonson et al. (1989). At that visit, data related to animals and herds were also collected and organized respectively, based on the origin or the genetic of the cow (imported purebred or native crossbred), the breed, the number of lactations, the day in milk (DIM), and the herd size and feeding.

\section{Feeding}

Data about feeding components are summarized in Table 1. There are two types of diet composition formula according to the herd size. Medium herd owners prepare their concentrate formulation and distribute a variety of forage; however, small herds use a prepared concentrate-based diet and distribute only straw as forage along the year with additional hay offered in winter. The grazing system of small herds performed in two seasons: stubble grazing and dry pasture in summer and early autumn and green grazing in spring; however, in medium herds, cows are raised indoors. All herds distribute forage and concentrate separately. Cows were fed $8 \mathrm{~kg}$ of concentrate, offered at two equally daily portions after milking.

\section{Study design}

The present work is a cross-sectional prevalence study, considering the individual cow as experimental unit and the prevalence of SCK as main outcome measurement. Hyperketonemia was defined as suggested by Ospina et al. (2010), and cows were considered as having SCK, if blood BHBA concentrations equal or exceed $1.2 \mathrm{mmol} / \mathrm{L}$. Each cow was tested only once for BHBA blood level, between 2 and 50 DIM. 16 dairy herds were selected from the list of dairy herds recorded in the veterinary services of Merouana's district based on their willingness to participate and the number of cows.

Table 1 Components of feeding in the studied herds

\begin{tabular}{lll}
\hline Ingredient & Medium herds & Small herds \\
\hline Concentrate composition & $40 \mathrm{~kg}$ of corn & $30 \mathrm{~kg}$ of corn \\
Quantity in 100 kg & $15 \mathrm{~kg}$ of soy & $6 \mathrm{~kg}$ of soy \\
& $22 \mathrm{~kg}$ of bran & $63 \mathrm{~kg}$ of bran \\
& $22 \mathrm{~kg}$ of barley & $1 \mathrm{~kg}$ of VMC \\
& $1 \mathrm{~kg}$ of VMC & \\
Forage composition & $15 \mathrm{~kg}$ of lucerne & Hay of lucerne \\
& $15 \mathrm{~kg}$ of corn silage or & added in \\
& oat & winter \\
& Straw ad libitum & Straw ad libi- \\
& & tum \\
\hline
\end{tabular}

$V M C$ vitamin mineral complex 


\section{The SCK diagnosis}

Two types of whole blood samples were collected from the caudal and the jugular vein of each cow, for respectively, BHBA and metabolic parameter determination. The samples were performed always at the same time, approximately 4 to $5 \mathrm{~h}$ after morning concentrate distribution. The first one was performed using a 19-gauge needle attached to a syringe of $2.5 \mathrm{~mL}$ draw. Immediately after collection, blood BHBA concentration was determined in situ using a $\beta$-ketone test strip coupled to a cowside electronic meter (FreeStyle Optium $®$; Abbott Diabetes Care Ltd., Witney, UK) according to the manufacturer's instructions. The second one was collected in a vacutainer tube and let to clot for $60 \mathrm{~min}$ at room temperature prior to centrifugation. After a centrifugation at $3000 \mathrm{rpm}$ for $10 \mathrm{~min}$, the serum was aliquoted and stored at $-20^{\circ} \mathrm{C}$ until biochemical analysis.

\section{Biochemical analysis}

The stored serum was used to determine different parameters of metabolism (glucose, triglycerides, cholesterol, total protein, albumin, total bilirubin, urea, and creatinine), enzymes (aspartate aminotransferase (AST), alanine aminotransferase (ALT), and alkaline phosphatase (ALP)), and minerals (calcium, phosphorus, sodium, potassium, and chloride). Biochemical analyses were carried out using specific commercial diagnostic kits as follows: glucose, triglycerides, cholesterol, total protein, albumin, total bilirubin, urea, and creatinine (Cypress Diagnostics, Belgium); total bilirubin (Roche Diagnostics, Germany); ALT, AST, and PAL (Cypress Diagnostics, Belgium); and calcium and phosphorus (Spinreact, Spain).

The biochemical analyses were performed through an automated chemistry analyzer Mindray BS 200 (Bio-Medical Electronics Co., Ltd, China) according to protocols of the manufacturer. Serum sodium, potassium, and chloride were determined using Easylyte plus $\mathrm{Na} / \mathrm{K} / \mathrm{Cl}$ electrolyte analyzer (Medica Corporation, USA), a fully automated system based on ion selective electrode (ISE) method, using solution pack kit.

\section{Statistical analysis}

The data were analyzed using the statistical software SPSS version 20.0. All variables were presented as mean and standard of deviation (SD) or median and interquartile range (IQR) according to data distribution, normally and non-normally, respectively. A value of $P \leq 0.05$ was considered significant. The BHBA concentration was considered as a continuous variable. Student $t$ test was performed to compare the variation of metabolic blood values between cows with and without SCK. Pearson's correlation analyses were also conducted to evaluate relationships between blood BHBA and other metabolic parameters.
For logistic regression analyses, qualitative variables were dichtomised. The DIM was categorized as weeks. The origin or genetic of cows was categorized as imported or purebred $(n=44)$ and native or crossbred $(n=56)$, and the breed of cows as Holstein $(n=23)$ and Fleckvieh $(n=21)$. The rang of lactation was categorized as 1 (primiparous) and $\geq 2$ (multiparous). The BCS of cows was categorized as thin $(\leq 3.0)$ and fair (>3.0). The herds were classified according to their size into two herd-size classes: small (10-29), medium (30-50). Moreover, for linear regression analyses, blood BHBA values were converted to $\mathrm{mg} / \mathrm{dL}$ (initial unit was $\mathrm{mmol} / \mathrm{L}$ ) to avoid values of zero points, which are difficult to normalize. Afterwards, the data were normalized using a two-step approach for transforming continuous variables to normal (Templeton 2011).

For categorical variables, a chi-square test was performed to validate potential risk factors associated with SCK results; significant variables $(P \leq 0.05)$ were subjected to binary logistic regression. The SCK disease (binary variable) was considered as a dependent variable and the factors as independent variables. The final model was verified with the Hosmer and Lemeshow goodness of fit test (Hosmer et al. 2013). However, a linear stepwise regression was performed for numerical variables. The normalized BHBA was included in the model as dependent variable and all other metabolic variables were included as independent variables. As a final step in stepwise regression (forward stepwise elimination), all variables selected previously with a $P \geq 0.05$ were excluded. Collinearity between independent variables was verified in the two previously cited models by a correlation analysis, where variables with a strong collinearity (correlation coefficient $>0.9$ ) were excluded from the multiple analysis.

Finally, the cut-off points or critical thresholds of metabolic predictors for SCK diagnosis (dependent binary variable) were determined using receiver operating characteristic (ROC) analysis, where significant variables in correlation and regression analysis were subjected to this analysis. The area under the curve (AUC) was performed to evaluate the diagnostic precision of the selected parameters and only significant variables were selected for prediction $\left(\mathrm{H}_{0}\right.$ : $\mathrm{AUC}=0.5$ versus $\mathrm{H}_{1}$ : AUC $\neq 0.5 ; P \leq 0.05$ ). Youden's index was calculated to determine the optimal thresholds of the significant parameters.

\section{Results}

\section{Descriptive statistics}

The mean \pm SD of determined BHBA across all cows was $0.65( \pm 0.43) \mathrm{mmol} / \mathrm{L}$ ranging from 0.1 to $2.5 \mathrm{mmol} / \mathrm{L}$. The blood BHBA concentration in cows with and without SCK were respectively, $1.72( \pm 0.55) \mathrm{mmol} / \mathrm{L}$ and $0.55( \pm 0.23)$ $\mathrm{mmol} / \mathrm{L}$. The median (IQR) day for SCK diagnosis was 7 (3) 
Table 2 Univariate analysis of categorical variables for risk factors associated with subclinical ketosis (SCK)

\begin{tabular}{lllll}
\hline Factors & $\begin{array}{l}\text { Comparison } \\
\text { level }\end{array}$ & $\begin{array}{l}\text { Cows without } \\
\text { SCK (total } \\
n=91 \text { ) }\end{array}$ & $\begin{array}{l}\text { Cows with } \\
\text { SCK (total } \\
n=9 \text { ) }\end{array}$ & $P$ value \\
\hline Parity & Primiparous & 35 & 2 & 0.478 \\
& Multiparous & 56 & 7 & \\
BCS & $\leq 3.0$ "thin" & 37 & 7 & $\mathbf{0 . 0 4 1}$ \\
& $>3.0$ "fair" & 54 & 2 & \\
Genetic & Native & 49 & 7 & 0.292 \\
& Imported & 42 & 2 & 0.489 \\
Breed & Holstein & 21 & 2 & \\
& Fleckvieh & 21 & 0 & $\mathbf{0 . 0 3 1}$ \\
Herd size & Small & 43 & 8 & \\
& Medium & 48 & 1 & \\
\hline
\end{tabular}

*Variables selected and used in the multiple analysis $(P \leq 0.05)$

DIM. The median (IQR) lactation number was 2 (2) and 3 (3) in non-SCK and SCK cows, respectively. The median (IQR) BCS was 2.75 (1) in ketotic cows and 3 (1) in healthy cows.

\section{Prevalence}

The SCK was defined in the present study as BHBA concentrations higher or equal to $1.2 \mathrm{mmol} / \mathrm{L}$. At this cutoff point, the prevalence of SCK was $9 \%$ between 2 and 50 DIM. Using alternative thresholds such as $1.0,1.4$, and $1.7 \mathrm{mmol} / \mathrm{L}$ for SCK definition, the prevalence became respectively, $14 \%, 6 \%$, and $4 \%$.

All diagnosed cases of SCK have been observed in the first three weeks post-calving. The peak prevalence of SCK was observed during the first week followed by the second week at $55.6 \%$ and $33.3 \%$, respectively, while the remaining cases $(11.1 \%)$ were detected in the third week.

\section{Logistic regression analysis (risk factors for SCK)}

The results of independence analysis are presented in Table 2 and those of logistic regression in Table 3. Variables subjected to risk analysis were: parity, BCS, breed, genetic and herd size. In total, one herd-level factor and four animallevel factors. In the final model, the risk factors associated with SCK were: herd size $<30$ lactating cows and $\mathrm{BCS} \leq 3$.

\section{Parity}

The chi-square test did not show any significant differences between multiparous and primiparous regarding the occurrence of SCK $(P=0.041$; Table 2$)$. As can be seen in Table 1, the prevalence of SCK seems increasing in multiparous cows (7\%) compared to primiparous cows (2\%).

\section{BCS}

The BCS was assigned to each cow once by visual assessment. Interestingly, there is a significant effect of SCK on BCS $(P=0.478$; Table 2$)$. Thin cows $(\mathrm{BCS} \leq 3.0)$ were at significantly higher risk for developing SCK compared to fair cows $(P=0.058$; OR $=5.00,95 \% \mathrm{CI}=0.95-26.32$; Table 3).

\section{Breed}

The breed of cow did not affect the occurrence of SCK $(P=0.489 ;$ Table 2). It can be seen from the data in Table 2 that all imported purebred cows diagnosed with SCK were of Holstein breed.

\section{Genetic}

The results did not detect any significant difference related to the origin of cows on the occurrence of SCK $(P=0.292$; Table 2). The SCK seems to be more common in native cows ( 7 cases) than in cows imported ( 2 cases).

\section{Herd size}

There was a significant difference between SCK occurrence and herd size $(P=0.031$; Table 2$)$. Our findings also indicate
Table 3 Final logistic regression model of the association between BCS and herd size with the risk of SCK occurrence

\begin{tabular}{lllllll}
\hline Factors & Levels & Estimate & S.E & OR & $95 \%$ CI & $P$ value \\
\hline BCS & Fair & Referent & & & & \\
& Thin & 1.61 & 0.85 & 5.00 & $0.95-26.32$ & 0.058 \\
\multirow{2}{*}{ Herd size } & Medium & Referent & & & & \\
& Small & 2.17 & 1.09 & 8.76 & $1.03-74.49$ & 0.047 \\
Constant & & -4.83 & 1.20 & 0.01 & & 0.000 \\
\hline
\end{tabular}

Hosmer and Lemeshow test: chi-square $=3.879 ; d f=2 ; P=0.144 ; R^{2}=0.224$ 
Table 4 Univariate analysis of metabolic profile parameters comparison between ketotic and healthy cows and correlation between blood BHBA concentration and other metabolic parameters

\begin{tabular}{|c|c|c|c|c|c|}
\hline \multirow[t]{3}{*}{ Metabolic parameters } & \multicolumn{3}{|c|}{ Independent-samples $t$ test } & \multirow{2}{*}{\multicolumn{2}{|c|}{$\frac{\text { Pearson correlation test }}{\text { Blood BHBA }}$}} \\
\hline & \multirow{2}{*}{$\begin{array}{l}\text { SCK cows } \\
\text { Mean } \pm \sigma\end{array}$} & \multirow{2}{*}{$\begin{array}{l}\text { Healthy cows } \\
\text { Mean } \pm \sigma\end{array}$} & \multirow[t]{2}{*}{$P$ value } & & \\
\hline & & & & Corr. coef & $P$ value \\
\hline Albumin (g/L) & $27.19 \pm 5.17$ & $25.55 \pm 4.44$ & 0.33 & -0.12 & 0.231 \\
\hline Total protein $(\mathrm{g} / \mathrm{L})$ & $66.16 \pm 12.19$ & $69.44 \pm 15.55$ & 0.55 & 0.18 & 0.068 \\
\hline Total bilirubin (g/L) & $2.71 \pm 1.05$ & $4.87 \pm 1.62$ & $\mathbf{0 . 0 0 3} * *$ & 0.52 & $0.0001 * * *$ \\
\hline AST (IU/L) & $73.09 \pm 30.85$ & $76.66 \pm 19.18$ & 0.62 & 0.09 & 0.359 \\
\hline ALT (IU/L) & $21.27 \pm 11.69$ & $14.00 \pm 6.14$ & $0.008 * *$ & -0.05 & 0.634 \\
\hline ALP (IU/L) & $48.91 \pm 25.18$ & $39.77 \pm 12.29$ & 0.08 & 0.04 & 0.701 \\
\hline Urea $(\mathrm{g} / \mathrm{L})$ & $0.24 \pm 0.12$ & $0.27 \pm 0.08$ & 0.40 & 0.05 & 0.597 \\
\hline Creatinine (g/L) & $13.02 \pm 3.03$ & $10.92 \pm 1.74$ & $0.007 * *$ & -0.08 & 0.413 \\
\hline Cholesterol (g/L) & $0.94 \pm 0.36$ & $1.15 \pm 0.38$ & 0.15 & -0.04 & 0.711 \\
\hline Triglycerides (g/L) & $0.16 \pm 0.04$ & $0.20 \pm 0.10$ & 0.28 & 0.22 & $0.027 *$ \\
\hline Glucose (g/L) & $0.61 \pm 0.18$ & $0.44 \pm 0.10$ & $0.001 * *$ & -0.04 & 0.711 \\
\hline Phosphorus (mg/L) & $48.71 \pm 10.61$ & $48.33 \pm 5.65$ & 0.86 & 0.11 & 0.276 \\
\hline Calcium (mg/L) & $83.81 \pm 15.22$ & $83.11 \pm 31.02$ & 0.94 & -0.03 & 0.773 \\
\hline Sodium (mEq/L) & $152.70 \pm 18.46$ & $145.25 \pm 6.38$ & $0.02 *$ & -0.10 & 0.326 \\
\hline Potassium (mEq/L) & $4.55 \pm 0.74$ & $4.53 \pm 0.43$ & 0.91 & 0.01 & 0.949 \\
\hline Chloride (mEq/L) & $80.62 \pm 10.67$ & $82.00 \pm 4.30$ & 0.48 & 0.23 & $0.023 *$ \\
\hline
\end{tabular}

Corr. coef. correlation coefficient that the prevalence of SCK was lesser in medium-sized herds with 1 case against 8 cases recorded in small herds. Small herds have more risk for SCK compared with medium size herds $(\mathrm{OR}=8.76,95 \% \mathrm{CI}=1.03-74.49, P=0.047$; Table 3$)$.

Mean's comparison (metabolic status comparison between ketotic and healthy cows).

Metabolic parameters differences between cows with and without SCK are summarized in Table 4. When cows with SCK were compared to healthy cows, there were significant differences regarding bilirubin $(P=0.003)$, glucose $(P=0.001)$, ALT $(P=0.008)$, creatinine $(P=0.007)$, and sodium $(P=0.02)$. Total bilirubin showed higher values in cows with SCK compared to those without SCK, dissimilar to other significant parameters (glucose, ALT, creatinine and sodium) ketotic cows presented the lowest values.

\section{Pearson's correlation coefficients and regression analysis (metabolic parameters association with blood BHBA)}

The results of correlational analysis are presented in Table 4 and those of linear regression in Table 5. There was a positive correlation between BHBA and total bilirubin, triglycerides and chlorides with respective coefficients of correlation $0.52(P=0.000), 0.22(P=0.027)$, and 0.23 $(P=0.023)$ (Table 4$)$. After a forward stepwise elimination, four parameters statistically significant were retained in the finale model, which are: total bilirubin, chloride, sodium and phosphorus (Table 5). Interestingly, a good positive correlation is observed between BHBA and total bilirubin
$\left(R^{2}=0.59, P=0.000\right.$; Table 5). In Fig. 2, there is a clear linear association between blood BHBA and total bilirubin.

\section{ROC analysis (metabolic predictor selection and analysis)}

The metabolic predictors for SCK diagnosis were selected based on their coefficients in correlation and regression analysis, where the significant variables are selected. For prediction analysis only significant variables to AUC analysis (area $>5 ; P \leq 0.05)$ were retained. Total bilirubin was the only metabolic predictor $($ area $=0.890 ; P=0.0001$ ) with a discriminating ability for SCK detection. The optimal prediction threshold was determined by Youden's index $(J=0.7228 ; 95 \% \mathrm{CI}=0.3785$ to 0.8559$)$ for total bilirubin to be more than $4.09 \mathrm{~g} / \mathrm{L}(95 \% \mathrm{CI}=>3.14$ to $>5)$ with $77.78 \%$ sensitivity and $94.51 \%$ specificity (Table 6). Figure 3 presents the ROC plot of total bilirubin for SCK diagnosis.

Table 5 Association (final stepwise linear regression model) between BHBA and total bilirubin, chloride, chloride, and phosphorus

\begin{tabular}{lrrrl}
\hline Variables & Estimate & S.E & Beta & $P$ value \\
\hline Total bilirubin & 2.06 & 0.29 & 0.59 & 0.0001 \\
Chloride & 0.07 & 0.03 & 0.18 & 0.043 \\
Sodium & -0.04 & 0.02 & -0.17 & 0.034 \\
Phosphorus & 0.08 & 0.04 & 0.18 & 0.042 \\
Constant & -2.43 & 4.05 & & 0.549 \\
\hline
\end{tabular}

Model summary: $F=14.978 ; d f=4 ; P=0.000 ; R^{2}=0.387$ 
Fig. 2 Association (fitted line) between blood BHBA and total bilirubin

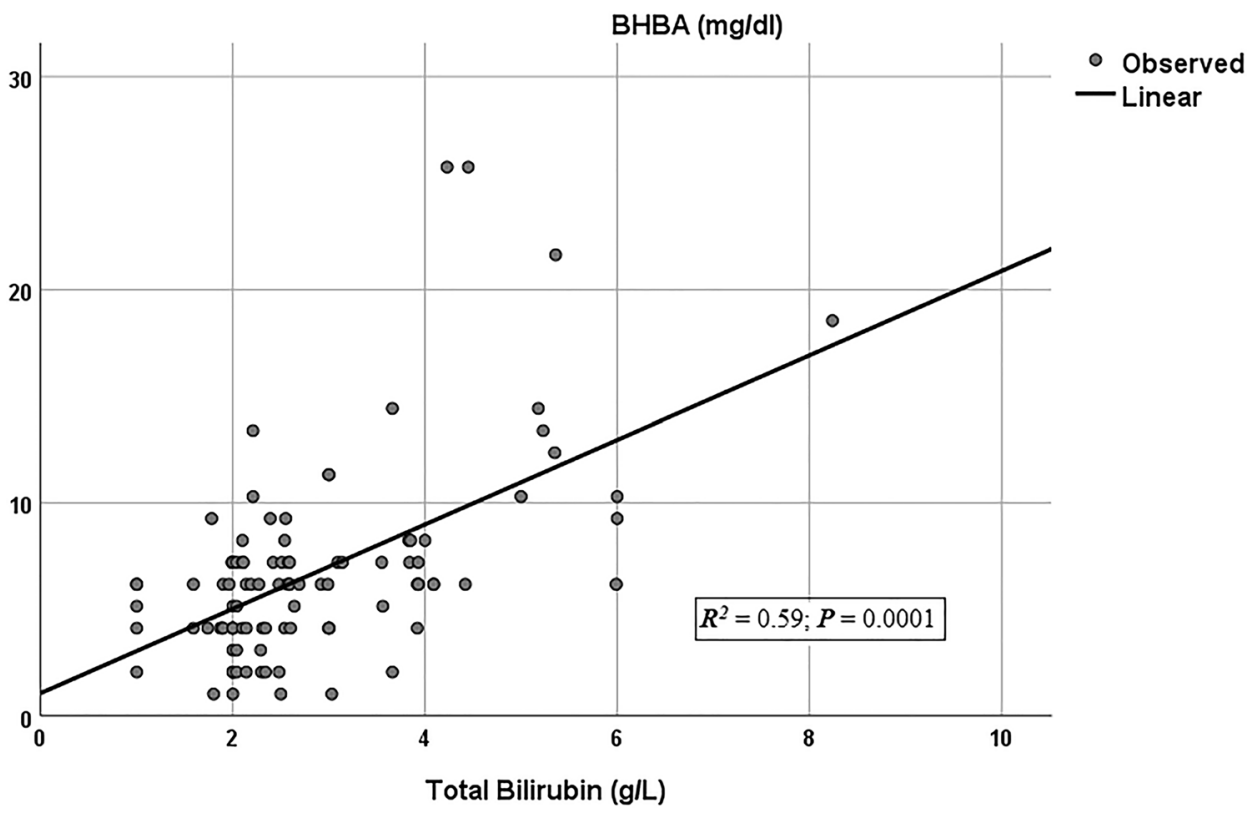

\section{Discussion}

Literature data showed a wide variation in the reported prevalence of bovine ketosis. Previous studies indicate that prevalence of SCK ranges from 6.9 to $14.1 \%$ in the first 2 months of lactation (Dohoo and Martin 1984; Andersson and Emanuelson 1985; Nielen et al. 1994; Duffield et al. 1997), whereas, recently, the peak prevalence of SCK in dairy cattle was noticed in the first 2 weeks of lactation, ranging from 20 to 43\% (Herdt 2000; Duffield et al. 2009; Chapinal et al. 2011; McArt et al. 2012; Suthar et al. 2013). Furthermore, a recent study covering wider geographic areas from different continents reported that SCK prevalence ranged approximately from 8 to $40 \%$ (Brunner et al. 2019). This variation of SCK prevalence across different countries is related to numerous factors, such as, the test characteristics (sensitivity and specificity), the threshold used for defining SCK, the screening period in post-calving (e.g., first week or month), the scheme of monitoring (testing once, twice or more) and test intervals (e.g., week, more or less).
The overall prevalence of SCK detected in our research was $9 \%$ between 2 to 50 DIM. Recently, it has been shown that the median time for SCK resolution is about 5 days; consequently, the weekly monitoring might underestimate the real incidence of SCK (McArt et al. 2012). Assessing the real incidence of SCK require testing twice or more in a week, because the weekly screening can potentially lead to development and resolution of SCK between test intervals.

Reported prevalence rates range from 11.2 to $36.6 \%$ in Western Europe (Suthar et al. 2013), from 26 to 56\% in North America (McArt et al. 2012), and from 8 to $40 \%$ in 12 different countries worldwide (Brunner et al. 2019). This variation is related to the difference in the scheme of sampling, the period of monitoring and the definition of SCK. Further explanations for the elevated incidence observed in Western productions systems is the higher milk production objectives. Garro et al. (2014) and Samiei et al. (2013) reported SCK prevalence of $10.3 \%$ and $12.2 \%$, respectively, which are about the same as reported in our study and share the similar protocol for sampling and defining SCK. Similarly, a recent study reported a
Table 6 Prediction threshold, $\mathrm{Se}, \mathrm{Sp},+\mathrm{LR},-\mathrm{LR}, \mathrm{NPV}, \mathrm{PPV}$, Acc, and area under the ROC curve for total bilirubin in cow SCK diagnosis

\begin{tabular}{llcl}
\hline Parameter & Statistic & Value & 95\% CI \\
\hline Total bilirubin threshold $(\mathbf{4 . 0 9} \mathbf{g} / \mathbf{L})$ & Sensitivity (Se) & $77.78 \%$ & 39.99 to $97.19 \%$ \\
& Specificity (Sp) & $94.51 \%$ & 87.64 to $98.19 \%$ \\
& Positive likelihood ratio (+LR) & 14.16 & 5.64 to 35.55 \\
& Negative likelihood ratio (-LR) & 0.24 & 0.07 to 0.80 \\
& Positive predictive value (PPV) & $58.33 \%$ & 35.79 to $77.86 \%$ \\
& Negative predictive value (NPV) & $97.73 \%$ & 92.68 to $99.32 \%$ \\
& Accuracy (Acc) & $93.00 \%$ & 86.11 to $97.14 \%$ \\
\hline
\end{tabular}

$\mathrm{AUC}=0.890 ; \mathrm{SE}=0.060 ; \mathrm{Z}=6.157 ; P=0.001 ; 95 \% \mathrm{CI}=0.812$ to 0.944 
Fig. 3 Curve receiver operating characteristic (ROC) plot of total bilirubin for diagnosis of SCK in dairy cattle

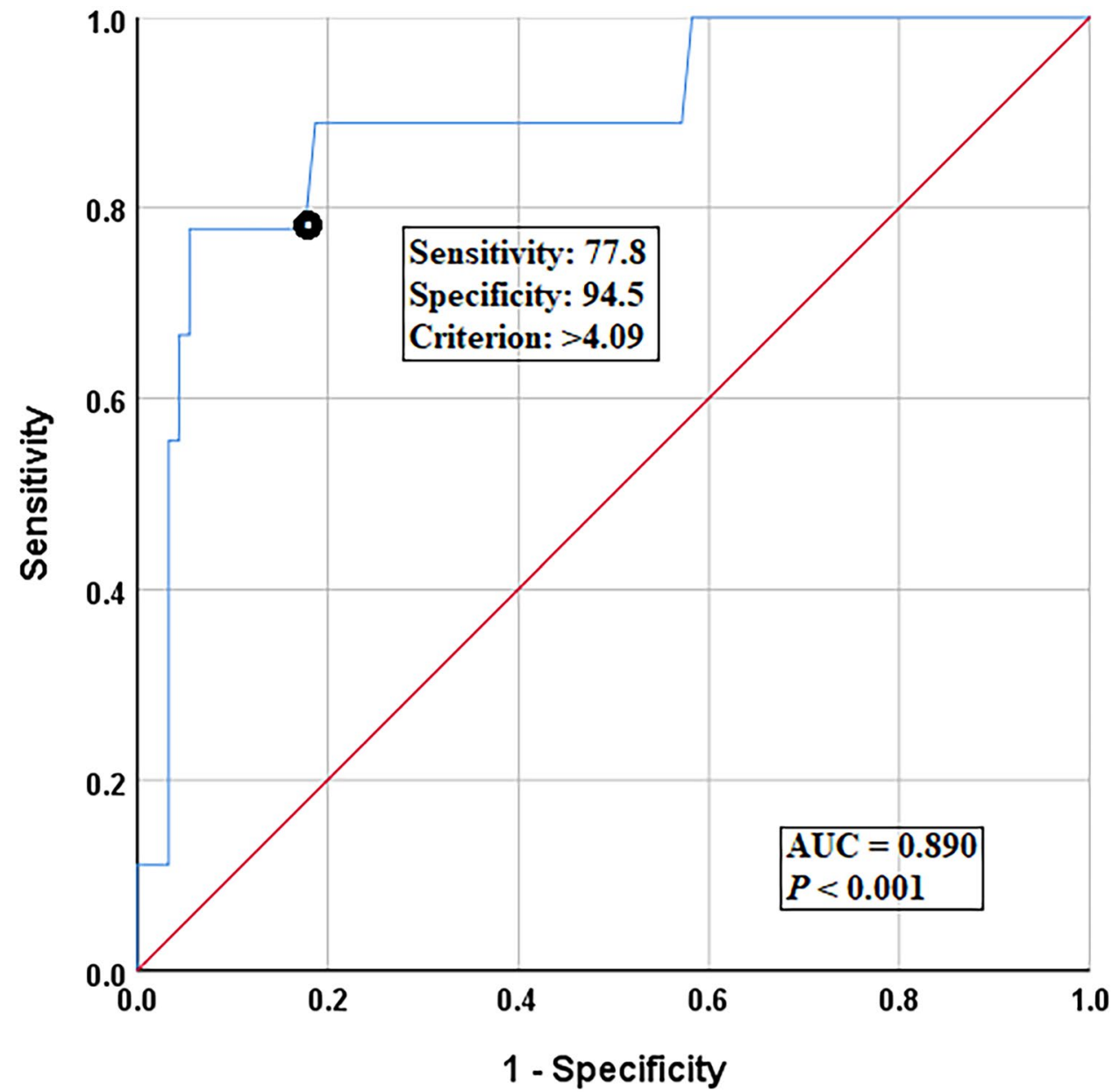

SCK prevalence of less than $10 \%$ in 2 countries (Australia and Colombia) out of 12 (Brunner et al. 2019). This later explain this difference in SCK prevalence at the level of countries by feeding and genetic variation, milk production objectives and management differences in dairy herds.

All cases of SCK have been diagnosed in the first three weeks post-calving, with a peak during the first and second weeks, followed by the third week. As reported previously, the peak prevalence of SCK occurred during the third and fourth week (Dohoo and Martin 1984; Andersson and Emanuelson 1985). Recently, it has been reported that the peak prevalence of SCK was mostly seen in the first two weeks postpartum (McArt et al. 2012; Suthar et al. 2013; Tatone et al. 2016). This recent finding corroborate with our outcomes and with those of Duffield (2000), who stated that advanced metabolic challenge closer to calving is a consequence of progress in genetics and feeding management.

Important risk factors influencing the occurrence of SCK include parity, BCS, genetics, herd and season. Herd-level differences regarding the prevalence of ketosis has been well documented (Duffield 2000).
In this study, the SCK prevalence was higher in multiparous cows but without significant effect. Most studies reported an increased risk of SCK occurrence in cows with higher parity ( $\geq 3$ ) (McArt et al. 2012; Suthar et al. 2013; Berge and Vertenten 2014; Garzón-Audor and Oliver-Espinosa 2019). This may be related to the higher NEB and lipid mobilization in multiparous than primiparous cows, in which energy depletion is related to both concomitant physiologic stages (gestation and lactation) (Berge and Vertenten 2014).

The present results suggest that thin cows $(\mathrm{BCS} \leq 3.0)$ are more prone to develop hyperketonemia than fair cows. Dissimilar to our outcomes, cows leading to overcondition (fatty), with $\mathrm{BCS} \geq 3.5$, have an increased risk of ketosis in early lactation (Gillund et al. 2001; McArt et al. 2015; Seifi et al. 2011). Moreover, it has been reported recently that cows with $\mathrm{BCS} \geq 3.0$ at calving have an increased risk of ketosis associated with enhanced lipolysis, leading to greater plasma concentrations of BHBA (Garzón-Audor and Oliver-Espinosa 2019). However, in early lactation, it's natural to think that thin cows have low-fat reserves, which make them unable to manage the higher energy and nutrient requirements made by milk production. Also, cows highly 
supplemented with simple sugars, could produce more BHBA not because of lipid mobilization (they don't need because they are not in NEB) but because of feeding (feed source BHBA).

The prevalence of SCK was significantly higher in small sized herds compared to medium size herds. Similarly, Berge and Vertenten (2014) reported a negative association between the size of lactating herd and the prevalence of ketosis. According to the same authors, herds with greater size have more pens related to lactation stages with specific dietary recommendations and higher nutritional services. Recently, it has been shown that large lactating herds were at higher risk for ketosis development (Garzón-Audor \& OliverEspinosa 2019). This later explains that large herds raise high lactating cows to maximize milk production as a consequence SCK risk increases. According to these contradictory findings we suppose that herd size can be a confounding factor because it is more related to herd management and feeding as well as individual cow variation (genetic selection).

The cow's breed did not affect the occurrence of SCK contrary to a previous (Andersson and Emanuelson 1985), and a more recent study who demonstrated that Jersey breed was more susceptible to ketosis compared to Holstein (Tatone et al. 2016). Similar to our results, other authors found no association between breed and ketosis occurrence (Berge and Vertenten 2014; Garzón-Audor and Oliver-Espinosa 2019).

The present research demonstrated that SCK was more common in native cows than in cows imported but without significant effect. All cases of SCK in native cows were observed in small herds and the most of imported cows were raised in medium herds with a good feeding and housing compared to small herds. We especulate that this genetic variation in SCK susceptibility could be more related to feeding practices. Further explanation for lower cases of SCK in exotic cows is their adaptability to local environmental conditions (heat stress and lack of forage). As we hypothesized, van der Drift et al. (2012) evokes that environmental factors affect more the ethology of hyperketonemia in herds compared to genetic aspects. We think that under harsh conditions, cows with high production potential might adapt by reducing milk than expected based on their breeding value, but further investigations are needed.

The concentration of glucose was significantly lower in ketotic cows than healthy. Similarly, other authors have reported a significant lower glucose level in ketotic cows and compared to healthy (Sun et al. 2015; Cao et al. 2017; Yang et al. 2019). In the same view, a recent study showed that hypoglycemia affects roughly one-third of hyperketonemic cows (Dubuc and Buczinski 2018). Moreover, statistically significant higher blood levels of total bilirubin were found in ketotic cows. In the same vein, the blood total bilirubin levels were higher in cows with SCK compared to those without (Sun et al. 2015; Yang et al. 2019). The significant difference observed in glucose and total bilirubin may be related in part to anorexia and in other part to the stressing effect of lipomobilization and ketone bodies accumulation on liver; this hepatic accumulation may decrease the processes of gluconeogenesis for glucose and reduce the excretory capacity for total bilirubin. However, the blood ALT, creatinine and sodium values recorded in the present study were slightly lower in hyperketonemic cows but within physiological limits and without pathophysiological signification.

Pearson's correlation coefficients and linear regression analysis demonstrated a reliable association between BHBA and total bilirubin. This finding supports previous research, which reported a good positive correlation between acetoacetate and total bilirubin (Kauppinen 1984; Ropstad et al. 1989). Our findings regarding relations between BHBA and bilirubin but not between BHBA and ASAT are consistent with results reported by Pechová and Nečasová (2018).

An important finding in our work was the excellent discriminating ability of total bilirubin for SCK diagnosis using the threshold $4.09 \mathrm{~g} / \mathrm{L}(77.78 \%$ sensitivity and $94.51 \%$ specificity). Sun et al. (2015) reported that total bilirubin concentration more than $3.3 \mathrm{mmol} / \mathrm{L}$ indicates abnormal liver function and can also be considered as a predictor for a high risk of ketosis (58\% sensitivity and $83 \%$ specificity). This later considered total bilirubin as indicator reflecting the capacity of the liver for excretion, secretion and detoxication, which is in agreement with our results.

According to the metabolic profile which indicates a lower glycemia and higher total bilirubin in ketotic cows and higher cases of SCK in small herds in which the quality of feeding is lower compared to medium herds, we suggest that observed hyperketonemia in our study is type I which related to low energy density of rations.

\section{Conclusion}

This study allowed obtaining first report on the prevalence of SCK and the associated risk factors in Algeria. The prevalence was $9 \%$ and lower BCS, advanced parity and decreased herd size were considered as major risk factors for developing SCK in dairy cows in the early lactation (2 to 50 DIM). Also, SCK occurs mostly within the first 2 weeks postpartum (with a peak at the first week), which make this period the best for monitoring to maximize detection and reduce negative economic impacts. At the metabolic level, cows with SCK presented a lower glycemia and a higher total bilirubin level compared to healthy ones. Interestingly, a good positive correlation is observed between BHBA and total bilirubin, that showed the best prediction potential of SCK. We suggest that ketosis type I is the dominated one in our study. Further studies are required to validate other 
metabolic predictors for SCK diagnosis and investigate on feeding and adaptation of imported highly yielding cows in semiarid regions in the eastern of Algeria.

Acknowledgements Special thanks to the laboratory of biochemistry related to the University Hospital Center of Sétif for laboratory analysis. The authors would like to thank Dr Abdelkader Gasmi for its technical support and laboratory data recording used in this study.

Author contribution A.Azizi, K. Deghnouche and M. Tlidjane: conceptualization, methodology. A. Azizi and A. Achouri: farm visit and sampling. Azizi A. and K. Ghouguel: statistical analysis. K. Deghnouche: laboratory analysis.||A. Azizi: writing-original draft preparation. A. Azizi and E. González-García: writing—reviewing and editing.

Availability of data and material The datasets generated during the current study are available from the corresponding author on reasonable request.

Code availability Not applicable.

\section{Declarations}

Ethical approval The sampling and data collection in this study was performed by certified veterinarians that respected the ethical recommendations of the Algerian government.

Consent to participate The authors get, from all animal owners, verbal informed consent prior to the sampling and the data recording at level of animal and farm.

Consent for publication All authors read and consent the publication of the manuscript.

Conflict of interest The authors declare no competing interests.

\section{References}

Andersson L, Emanuelson U (1985) An epidemiological study of hyperketonaemia in Swedish dairy cows; determinants and the relation to fertility. Prev Vet Med 3(5):449-462

Berge AC, Vertenten G (2014) A field study to determine the prevalence, dairy herd management systems, and fresh cow clinical conditions associated with ketosis in western European dairy herds. J Dairy Sci 97(4):2145-2154. https://doi.org/10.3168/jds. 2013-7163

Brunner N, Groeger S, Canelas Raposo J, Bruckmaier RM, Gross JJ (2019) Prevalence of subclinical ketosis and production diseases in dairy cows in Central and South America, Africa, Asia, Australia, New Zealand, and Eastern Europe. Translational Animal Science 3(1):84-92. https://doi.org/10.1093/tas/txy102

Cao Y, Zhang J, Yang W, Xia C, Zhang H-Y, Wang Y-H, Xu C (2017) Predictive value of plasma parameters in the risk of postpartum ketosis in dairy cows. Journal of Veterinary Research 61(1):9195. https://doi.org/10.1515/jvetres-2017-0011

Chapinal N, Carson M, Duffield TF, Capel M, Godden S, Overton M, Santos JEP, LeBlanc SJ (2011) The association of serum metabolites with clinical disease during the transition period. J Dairy Sci 94(10):4897-4903. https://doi.org/10.3168/jds.2010-4075

Direction des Services Agricoles de la Wilaya de Batna (2020) Rapport d'activité annuelle (Accessed on January 2021).
Dohoo IR, Martin SW (1984) Subclinical ketosis: prevalence and associations with production and disease. Can J Comp Med 48(1): 1

Dubuc J, Buczinski S (2018) Short communication: Cow- and herdlevel prevalence of hypoglycemia in hyperketonemic postpartum dairy cows. J Dairy Sci 101(4):3374-3379. https://doi.org/10. 3168/jds.2017-13773

Duffield T (2000) Subclinical ketosis in lactating dairy cattle. The Veterinary clinics of North America. Food animal practice 16(2):231-53, v.

Duffield TF, Kelton DF, Leslie KE, Lissemore KD, Lumsden JH (1997) Use of test day milk fat and milk protein to detect subclinical ketosis in dairy cattle in Ontario. The Canadian Vet $\mathrm{J}$. La revue veterinaire canadienne 38(11):713-718.

Duffield TF, Lissemore KD, McBride BW, Leslie KE (2009) Impact of hyperketonemia in early lactation dairy cows on health and production. J Dairy Sci 92(2):571-580. https://doi.org/10.3168/ jds.2008-1507

Edmonson AJ, Lean IJ, Weaver LD, Farver T, Webster G (1989) A body condition scoring chart for Holstein dairy cows. J Dairy Sci 72(1):68-78

Enjalbert F, Nicot MC, Bayourthe C, Moncoulon R (2001) Ketone bodies in milk and blood of dairy cows: relationship between concentrations and utilization for detection of subclinical ketosis. J Dairy Sci 84(3):583-589. https://doi.org/10.3168/jds. S0022-0302(01)74511-0

Garro CJ, Mian L, Cobos Roldán M (2014) Subclinical ketosis in dairy cows: prevalence and risk factors in grazing production system. J Anim Physiol Anim Nutr 98(5):838-844

Garzón-Audor A, Oliver-Espinosa O (2019) Incidence and risk factors for ketosis in grazing dairy cattle in the Cundi-Boyacencian Andean plateau. Colombia Tropical Animal Health and Production 51(6):1481-1487. https://doi.org/10.1007/s11250-019-01835-z

Gillund P, Reksen O, Gröhn YT, Karlberg K (2001) Body condition related to ketosis and reproductive performance in Norwegian dairy cows. J Dairy Sci 84(6):1390-1396. https://doi.org/10. 3168/jds.S0022-0302(01)70170-1

Herdt TH (2000) Ruminant adaptation to negative energy balance. Influences on the etiology of ketosis and fatty liver. The Veterinary clinics of North America. Food animal practice 16(2):215$30, \mathrm{v}$.

Hosmer DW, Lemeshow S, Sturdivant RX editors (2013) Applied logistic regression. 3rd ed. Wiley series in probability and statistics. Wiley, Hoboken.

Ingvartsen KL (2006) Feeding- and management-related diseases in the transition cow. Anim Feed Sci Technol 126(3-4):175-213. https://doi.org/10.1016/j.anifeedsci.2005.08.003

Iwersen M, Falkenberg U, Voigtsberger R, Forderung D, Heuwieser W (2009) Evaluation of an electronic cowside test to detect subclinical ketosis in dairy cows. J Dairy Sci 92(6):2618-2624. https:// doi.org/10.3168/jds.2008-1795

Kauppinen K (1984) ALAT, AP, ASAT, GGT, OCT activities and urea and total bilirubin concentrations in plasma of normal and ketotic dairy cows. Zentralbl Veterinarmed [a] 31(8):567-576. https://doi. org/10.1111/j.1439-0442.1984.tb01316.x

McArt JA, Nydam DV, Oetzel GR (2012) Epidemiology of subclinical ketosis in early lactation dairy cattle. J Dairy Sci 95(9):50565066. https://doi.org/10.3168/jds.2012-5443

McArt JA, Nydam DV, Oetzel GR (2013) Dry period and parturient predictors of early lactation hyperketonemia in dairy cattle. $\mathrm{J}$ Dairy Sci 96(1):198-209. https://doi.org/10.3168/jds.2012-5681

McArt JA, Nydam DV, Overton MW (2015) Hyperketonemia in early lactation dairy cattle: a deterministic estimate of component and total cost per case. J Dairy Sci 98(3):2043-2054. https://doi.org/ $10.3168 /$ jds.2014-8740 
Nielen M, Aarts MG, Jonkers AG, Wensing T, Schukken YH (1994) Evaluation of two cowside tests for the detection of subclinical ketosis in dairy cows. Can Vet J 35(4):229

Oetzel (GR) (2004) Monitoring and testing dairy herds for metabolic disease. The Veterinary clinics of North America. Food animal practice 20(3):651-674. https://doi.org/10.1016/j.cvfa.2004.06. 006.

Ospina PA, Nydam DV, Stokol T, Overton TR (2010) Association between the proportion of sampled transition cows with increased nonesterified fatty acids and beta-hydroxybutyrate and disease incidence, pregnancy rate, and milk production at the herd level. J Dairy Sci 93(8):3595-3601. https://doi.org/10.3168/jds. 2010-3074

Pechová A, Nečasová A (2018) The relationship between subclinical ketosis and ruminal dysfunction in dairy cows. Annals of Animal Science 18(4):955-971. https://doi.org/10.2478/aoas-2018-0038

Pourhoseingholi MA, Vahedi M, Rahimzadeh M (2013) Sample size calculation in medical studies. Gastroenterology and Hepatology from Bed to Bench 6(1):14-17

Ropstad E, Halse K, Refsdal AO (1989) Variations in parameters of liver function and plasma progesterone related to underfeeding and ketosis in a dairy herd. Acta Veterin Scandi 30(2).

Samiei A, Liang JB, Ghorbani GR, Hirooka H, Ansari-Mahyari S, Sadri H (2013) Prevalence of ketosis and its correlation with lactation stage, parity and peak of milk yield in Iran. Asian Journal of Animal and Veterinary Advances 8(4):604-612

Seifi HA, LeBlanc SJ, Leslie KE, Duffield TF (2011) Metabolic predictors of post-partum disease and culling risk in dairy cattle. Vet $\mathrm{J}$ 188(2):216-220. https://doi.org/10.1016/j.tvj1.2010.04.007

Sun Y, Wang B, Shu S, Zhang H, Xu C, Wu L, Xia C (2015) Critical thresholds of liver function parameters for ketosis prediction in dairy cows using receiver operating characteristic (ROC) analysis. Vet Q 35(3):159-164. https://doi.org/10.1080/01652176.2015. 1028657
Suthar VS, Canelas-Raposo J, Deniz A, Heuwieser W (2013) Prevalence of subclinical ketosis and relationships with postpartum diseases in European dairy cows. J Dairy Sci 96(5):2925-2938. https://doi.org/10.3168/jds.2012-6035

Tatone EH, Gordon JL, Hubbs J, LeBlanc SJ, DeVries TJ, Duffield TF (2016) A systematic review and meta-analysis of the diagnostic accuracy of point-of-care tests for the detection of hyperketonemia in dairy cows. Prev Vet Med 130:18-32. https://doi.org/10.1016/j. prevetmed.2016.06.002

Templeton GF (2011) A two-step approach for transforming continuous variables to normal: implications and recommendations for IS research. CAIS 28. https://doi.org/10.17705/1CAIS.02804

Tlidjane M, Alloui N, Deghnouche K, Alloui O (2004) Cas de cétose subclinique en Algérie. http://www.journees3r.fr/IMG/pdf/2004_ Sante_14_Tlidjane.pdf. (Accessed 15 May 2014).

van der Drift SGA, van Hulzen KJE, Teweldemedhn TG, Jorritsma R, Nielen M, Heuven HCM (2012) Genetic and nongenetic variation in plasma and milk $\beta$-hydroxybutyrate and milk acetone concentrations of early-lactation dairy cows. J Dairy Sci 95(11):6781-6787

Voyvoda H, Erdogan H (2010) Use of a hand-held meter for detecting subclinical ketosis in dairy cows. Res Vet Sci 89(3):344-351. https://doi.org/10.1016/j.rvsc.2010.04.007

Yang W, Zhang B, Xu C, Zhang H, Xia C (2019) Effects of ketosis in dairy cows on blood biochemical parameters, milk yield and composition, and digestive capacity. Journal of Veterinary Research 63(4):555-560. https://doi.org/10.2478/jvetres-2019-0059

Publisher's Note Springer Nature remains neutral with regard to jurisdictional claims in published maps and institutional affiliations. 


\section{Terms and Conditions}

Springer Nature journal content, brought to you courtesy of Springer Nature Customer Service Center GmbH ("Springer Nature").

Springer Nature supports a reasonable amount of sharing of research papers by authors, subscribers and authorised users ("Users"), for smallscale personal, non-commercial use provided that all copyright, trade and service marks and other proprietary notices are maintained. By accessing, sharing, receiving or otherwise using the Springer Nature journal content you agree to these terms of use ("Terms"). For these purposes, Springer Nature considers academic use (by researchers and students) to be non-commercial.

These Terms are supplementary and will apply in addition to any applicable website terms and conditions, a relevant site licence or a personal subscription. These Terms will prevail over any conflict or ambiguity with regards to the relevant terms, a site licence or a personal subscription (to the extent of the conflict or ambiguity only). For Creative Commons-licensed articles, the terms of the Creative Commons license used will apply.

We collect and use personal data to provide access to the Springer Nature journal content. We may also use these personal data internally within ResearchGate and Springer Nature and as agreed share it, in an anonymised way, for purposes of tracking, analysis and reporting. We will not otherwise disclose your personal data outside the ResearchGate or the Springer Nature group of companies unless we have your permission as detailed in the Privacy Policy.

While Users may use the Springer Nature journal content for small scale, personal non-commercial use, it is important to note that Users may not:

1. use such content for the purpose of providing other users with access on a regular or large scale basis or as a means to circumvent access control;

2. use such content where to do so would be considered a criminal or statutory offence in any jurisdiction, or gives rise to civil liability, or is otherwise unlawful;

3. falsely or misleadingly imply or suggest endorsement, approval, sponsorship, or association unless explicitly agreed to by Springer Nature in writing;

4. use bots or other automated methods to access the content or redirect messages

5. override any security feature or exclusionary protocol; or

6. share the content in order to create substitute for Springer Nature products or services or a systematic database of Springer Nature journal content.

In line with the restriction against commercial use, Springer Nature does not permit the creation of a product or service that creates revenue, royalties, rent or income from our content or its inclusion as part of a paid for service or for other commercial gain. Springer Nature journal content cannot be used for inter-library loans and librarians may not upload Springer Nature journal content on a large scale into their, or any other, institutional repository.

These terms of use are reviewed regularly and may be amended at any time. Springer Nature is not obligated to publish any information or content on this website and may remove it or features or functionality at our sole discretion, at any time with or without notice. Springer Nature may revoke this licence to you at any time and remove access to any copies of the Springer Nature journal content which have been saved.

To the fullest extent permitted by law, Springer Nature makes no warranties, representations or guarantees to Users, either express or implied with respect to the Springer nature journal content and all parties disclaim and waive any implied warranties or warranties imposed by law, including merchantability or fitness for any particular purpose.

Please note that these rights do not automatically extend to content, data or other material published by Springer Nature that may be licensed from third parties.

If you would like to use or distribute our Springer Nature journal content to a wider audience or on a regular basis or in any other manner not expressly permitted by these Terms, please contact Springer Nature at

onlineservice@springernature.com 